\title{
RF MEMS continuous reversible variable inductor based on a microfluidic network
}

\author{
Issam El Gmati ${ }^{1,2}$, Pierre Francois Calmon ${ }^{1}$, Ali Boukabache ${ }^{1}$, Patrick Pons ${ }^{1}$, Hatem Boussetta ${ }^{2}$, \\ Mouhamed Adel Kallala ${ }^{2}$, Kamel Besbes ${ }^{2}$ \\ 1 LAAS-CNRS, Université de Toulouse, CNRS, UPS, Toulouse, France \\ 2 Laboratoire de microelectronique et instrumentation, 5000 Monastir, Tunisia
}

\begin{abstract}
In this work, RF MEMS continuous reversible variable inductor has been fabricated by using microelec-tronic technology and lamination process. We review, evaluate and compare this variable inductor with other work. The proposed inductor is a dual circular coil and has an inductance of few $\mathrm{nH}$. The fundamental idea is to place a liquid droplet between the metal turns of a coil in order to modify the capacitive/resistive coupling between metal tracks and hence to change the stored magnetic energy. The SU-8 resin was used to realize the microfluidic channels and Au as metallic tracks. To prove the reversibility of the inductor, two cases were studied: filling and emptying of channels. The tuning range of the inductance is approxi-mately $107 \%$ at $1.6 \mathrm{GHz}$, making these devices very suitable as building blocks in many RF applications.
\end{abstract}

\section{Introduction}

Tunable inductors are important building blocks in many radio-frequency (RF) applications such as voltage-con-trolled-oscillators, tunable filters and antennas, and adaptative impedance matching circuits (Yoshihara et al. 2005; Ito et al. 2005; Lucyszun and Robertson 1994). Most of these applications required a high quality factor and wide tuning range. Many techniques were developed to tune the inductance value, most of which rely on the variation of the distance between two inductors to change the mutual coupling, as in (Lubecke et al. 2001; Tassetti et al. 2004; Zine-El-Abidine et al. 2005). A bus of switches was used in (Zhou et al. 1999) to select a certain number of turns of a spiral inductor resulting in a set of selectable discrete values of inductance. A magnetic core sliding inside a solenoid inductor was used in (Sarkar et al. 2005). In this paper we present an RF MEMS continuous reversible inductor with a large tuning range. The variability of the inductance varies according to the liquid position, which can be increased from zero to the total spiral length (I). RF the MEMS continuous reversible inductor is compared with each other in relation to some parameters such as tuning range, quality factor, self resonance frequency, excitation method and tuning method.

\section{Principe of variable inductor}

The proposed inductor, represented in Fig. 1, is a dual circular coil designed to have an expected inductance value of a few $\mathrm{nH}$. The metallic ( $\mathrm{Au}$ ) lines of the inductor have $20 \mathrm{~lm}$ widths, spaced by 10 $\mathrm{Im}$, while the inside and outside coil diameters are around 600 and 1,200 Im respectively. The dual spires must be fabricated inside the $70 \mathrm{~lm}$ width channel. When liquid moves along this channel, it changes the capacitive coupling between inter-spires leading to reduction of the stored magnetic energy, and hence scales down the inductance. The inductance value varies according to the liquid position, which can be increased from zero to the total spiral length (I). 


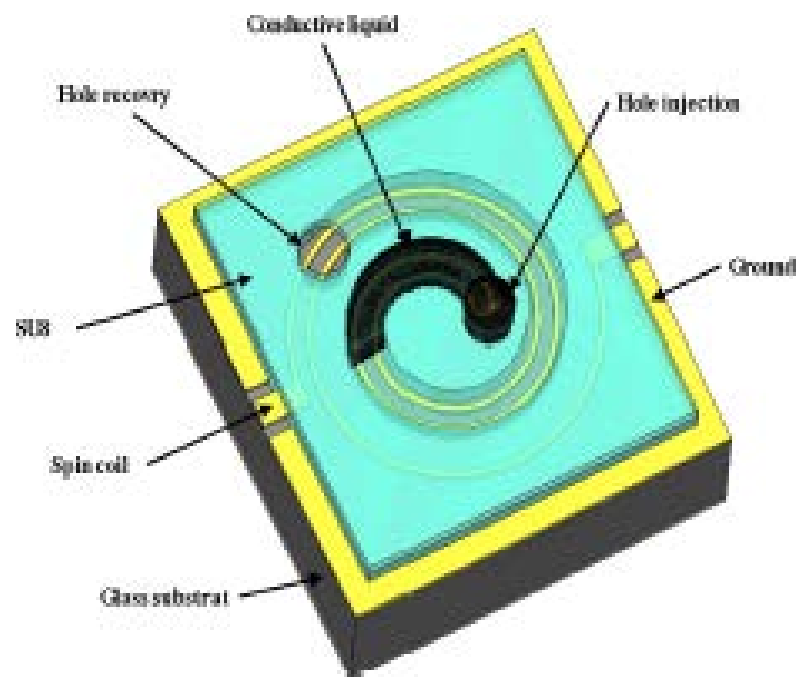

Fig. 1 Top view of the 3D model structure of the proposed variable inductor

\section{Design and realization}

The principal technological steps used to fabricate our devices is represented in Fig. 2 and show the sequential operations allowing to obtain thick gold spiral inductors deposited on a glass substrate. The technological process requires six masks level.

\subsection{Gold spiral inductors}

A Ti/Au (500/500A $)$ seed layer was homogeneously evaporated on the top side of a $500 \mathrm{~lm}$ thick glass substrate (Fig. 2a). A positive photoresist (AZ 4,562) was subsequently patterned in order to create the electroplating mould (thickness \&5.5 Im) (Fig. 2b). Then, 2-Im-thick gold lines, was electroplated into the resist mould and the latter was finally removed and the seed layer was chemically etched (Fig. 2c).

\subsection{Microfluidic channel}

In order to obtain channels with subsequent high aspect ratio, we have used the photosensitive resin SU-8 as a structural material. A $10 \mathrm{Im}$ thick film was firstly deposited by spin coating $4 \mathrm{ml}$ of SU-8 3,005 at $900 \mathrm{rpm}$ with $900 \mathrm{rpm} \mathrm{s}-1$ acceleration for $30 \mathrm{~s}$. The resist was then soft baked during $1 \mathrm{~min}$ at 65 [C, ramped at a rate of 10 ] $\mathrm{Cmin}-1$ up to 95 ]C, held at 95 a for 7 min and finally cooled down to room temperature. The resist was then exposed to UV light (90 $\mathrm{mJ} \mathrm{cm}-2)$, and post-baked during $1 \mathrm{~min}$ at 65 a $\mathrm{C}$ and $3 \mathrm{~min}$ at 95 ? $\mathrm{C}$ to cross-link the photoresist. Finally, the resist was developed in PGMEA developer (Propylene Glycol Methyl Ether Acetate) during 9 min (Fig. 2d).

A photosensitive SU-8 dry film, $10 \mathrm{~lm}$ in thickness, was then laminated on the glass wafer. A lamination pressure of two bars and a temperature of 65 a $\mathrm{C}$ were used to ensure perfect adhesion between SU-8 films. This new glass/SU-8 wafer is used as a classical wafer and the laminated SU-8 layer can be patterned using classical UV equipment and appropriate mask. Access holes are then opened into SU8 layer in order to reach embedded channels (Fig. 2e). The alignment between the different layers are obtained classically thank to gold alignment marks fabricated during the first steps. This process steps are described in detail in Fulcrand et al. (2009); Abgrall et al. (2006). 

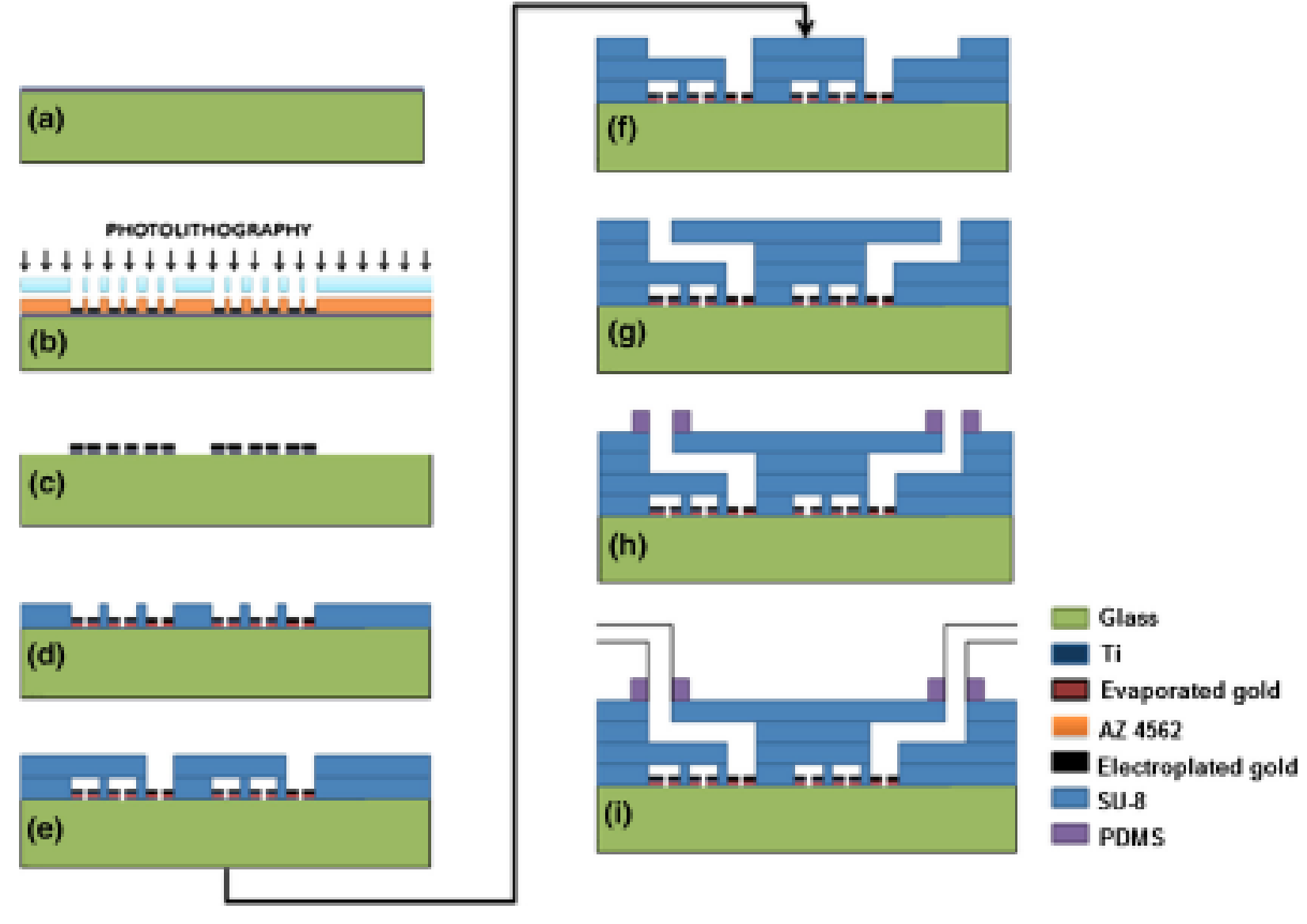

\subsection{Microfluidic access}

Microfluidic access channel was then performed by the same lamination technique. A second photosensitive SU-8 dry film (10 Im in thickness) was laminated and patterned on top of the previously structure in order to realize the access channel walls (Fig. 2f).

Finally, a $10 \mathrm{Im}$ thick SU-8 dry film was laminated and patterned to close the access channel and create access holes for the fluid (Fig. 2g).

\subsection{Fluidic connexion}

In order to perform fluidic connection between micro-pipe and fluidic channels, polydimethylsiloxane (PDMS) disks were sealed at the microchip inlet and outlet using photo curable glue (Fig. $2 \mathrm{~h}-\mathrm{i}$ ).

Figure 3 shows the successful integration of circular inductance by combining standard electroplating technique and lamination process. A general view of a gold circular micro-inductor is given in Fig. 3a). The "inductance channel" in SU-8 presents an excellent alignment with micro-inductance (Fig. 3b). Access holes are opened in the SU-8 layer (Fig. 3C), a second photosensitive SU-8 dry film is laminated to realize the access channel walls (Fig. 3d), PDMS disks were sealed at the microchip (Fig. 3e) and the complete microsystem is represented in Fig. $3 f$ ).

\section{Experiments results}

The S-parameters were measured from 50 to $20 \mathrm{GHz}$ with an Agilent 8510 network analyzer and Microtech GSG probes Channels were filled with salt water using a syringe and molded PDMS blocks achieve the fluidic connection. The set-up is shown in Fig. 4. The inductance $L$ and the quality factor $Q$ were calculated by using the following equations.

$$
L=\frac{1}{2 \pi f} \operatorname{Im}\left(\frac{1}{Y_{11}^{\text {ind }}}\right)
$$




$$
Q=-\frac{\operatorname{Im}\left(\frac{1}{Y_{11}^{\text {ind }}}\right)}{\operatorname{Re}\left(\frac{1}{Y_{11}^{\text {ind }}}\right)}
$$

$Y^{\text {ind }}$ is the two-port admittance matrix of the de-embedded inductor. De-embedding was performed by using the formula

$$
Y^{\text {ind }}=Y^{\text {meas }}-Y^{\text {open }}
$$

where $Y^{\text {meas }}$ and $Y^{\text {open }}$ are the admittance matrices of the measured device and the open pattern, respectively. The scattering parameters (S-parameters) are measured at different input powers and the interconnect lines with open standard.

During the RF measurement, fluid was manually moved by connecting a syringe to one of the external tube. Figure 5 specifies the different liquid positions of salt water inside the channel used for the RF characterization. To prove the reversibility of the inductor, two cases were studied: filling and emptying of channels. As illustrated in Fig. 6a, the maximum quality factor is close to 12 and is obtained at $1.6 \mathrm{GHz}$ without liquid in the channel. At this frequency the minimum quality factor is around five when the entire channel is filled with salt water. The measured inductance at $1.6 \mathrm{GHz}$ can be tuned from 5.4 down to $2.6 \mathrm{nH}$ (Fig. 6b). Once the channels are filled with salt water, it makes the handling of emptying channel through the same positions of fluid positions.

Figures 7 show respectively the variations of the measured results (I) versus saturated salt water positions (filling channels) at a frequency of $1.6 \mathrm{GHz}$. Most of the variation occurs for different liquid positions as was expected from the measured results 2 (emptying channels). It can be seen in Table 1 , that at $1.6 \mathrm{GHz}$ the tuning range of the inductor is above $107 \%$ and the Q-factor is between 5 and 12 . The measured results (II) differ slightly from the measured results two.

For the inductance (L) and the quality factor (Q) value, the differences are lower than 2 and $3 \%$ respectively and show in Fig. 8 . The effects of the droplet location in the microfluidic channel can cause this slight difference; in fact the droplet may either be in direct contact with the solid metal or it could form a capacitive contact through a thin layer. When the droplet or slug is removed from the RF signal path, the inductance presents very low loss that is dominated by the transmission line loss itself. These results demonstrate reversibility of the inductance.

\section{Comparison with other work}

A few variable inductors are already documented in literature in order to obtain tuned inductors. In Zhou et al. (1999), inductance variability was accomplished through the use of micro relays. While large inductance changes were possible, the values were discrete and the maximum quality factor was 3.3. A continuous variation of the inductance can be achieved by altering the mutual inductance of closely coupled coils by changing the distance between them (Lubecke et al. 2001); by this way, a tuning range of $18 \%$ was achieved with a quality factor of 12 . In Zine-El-Abidine et al. (2003), two bimorph, inductors were connected in parallel with the outer inductor fixed. The tuning range was $8 \%$ and the quality factor is not exceeding 9 at $5 \mathrm{GHz}$.

Electrostatic actuation was also used to change the gap between two inductors (Tassetti et al. 2004) the tuning range was closed to $50 \%$, but the quality factor was as low as three. Another technique consists to use a spiral inductor with a metal shield above it (Sugawara et al. 2004)it results with $38 \%$ of inductance variation when the separation between the inductors is changed. A spiral inductor fabricated with a flexible metal film (Yokoyama et al. 2003) can be used to change the spiral height, resulting in an inductance variation with a $10 \%$ maximum tuning range, and a 7.2 for the quality factor. In Chang and Sivoththaman (2006), tunable inductor was based on the bi-morph effect by using amorphous silicon deposited on aluminum layers: a $32 \%$ tuning range with high inductance (5.6-8.2 $\mathrm{nH}$ ) is achieved by the application of an electric potential. In (Kim and Peroulis 2009), the inductance of a spiral inductor is tuned by controlling the relative position of a magnetically coupled short circuited loop. The tunable inductor shows a measured *2:1 inductance tuning ratio over $25 \mathrm{GHz}$ with a 
maximum quality factor that varies between 10 and 26 . The main drawbacks of these tunable inductors are generally the low tuning range and quality factor. Table 2 presents the various studies cited in literature. They can be characterized by the fre-quency of work, the quality factor and the tuning range. In this work, we present a continuous reversible variable RF inductor. The tuned inductor is obtained through the salt water flowing inside the SU-8 micro-channel. Experiments give very interesting results compared to those obtained by the different approaches experienced up to now (Table 2): we have obtained inductance variation from 5.4 to $2.6 \mathrm{nH}$ with a tuning range of $107 \%$ at $1.6 \mathrm{GHz}$ frequency by using liquid circulation in 3D microfluidic RF MEMS developed in our laboratory. This approach gives the proof of potentialities offered by liquids to modify the RF behavior of inductors.
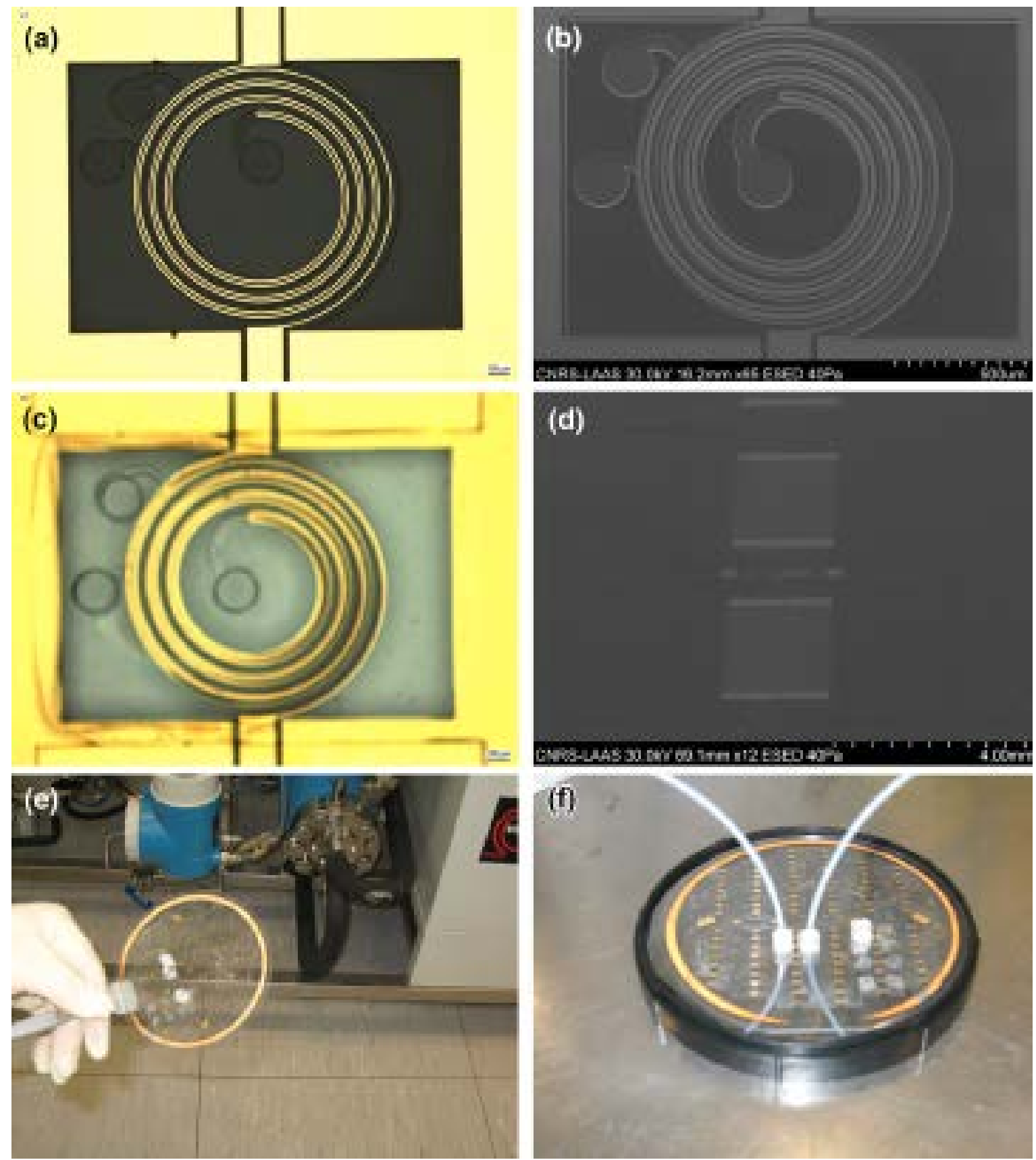

Fig. 3 Photographs of the studied devices during the fabrication process 


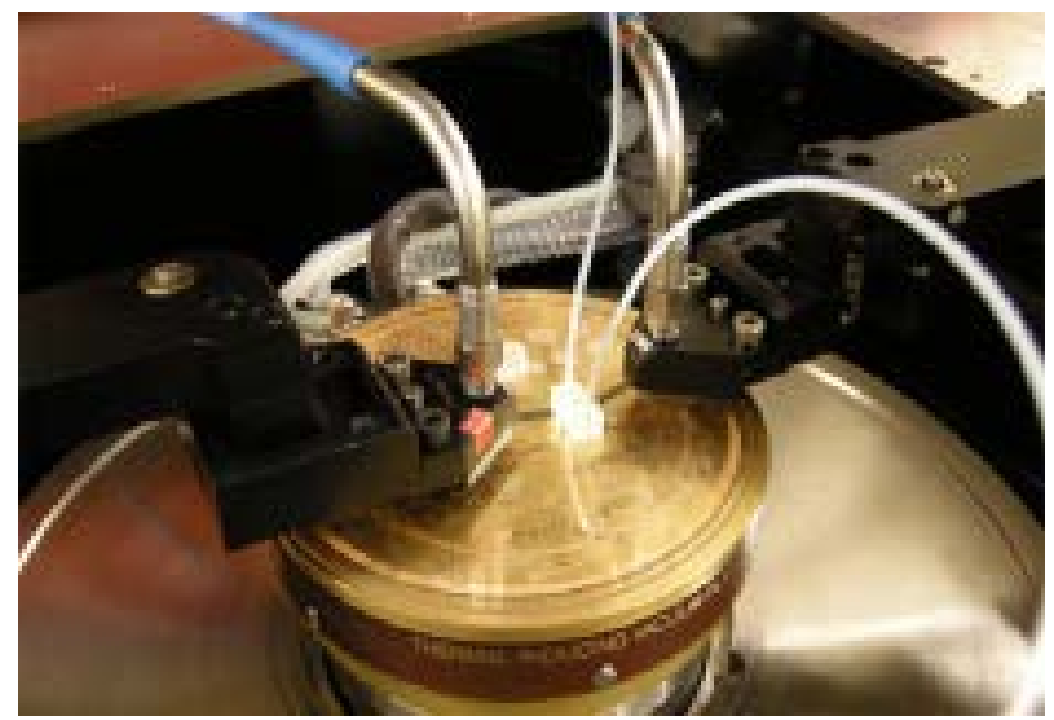

Fig. 4 Schematic drawing of the set-up

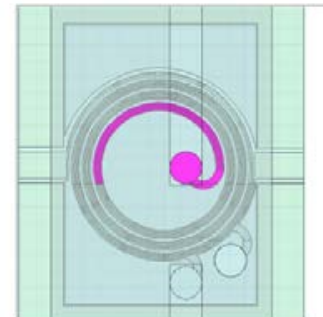

liquid position

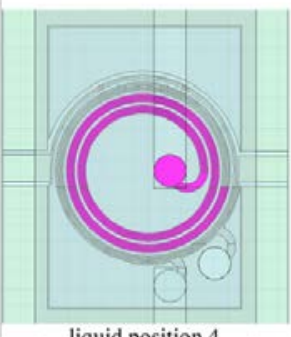

liquid position 4

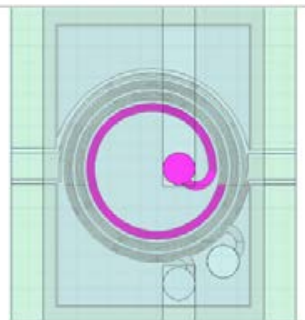

liquid position 2

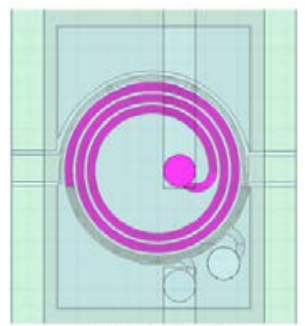

liquid position 5

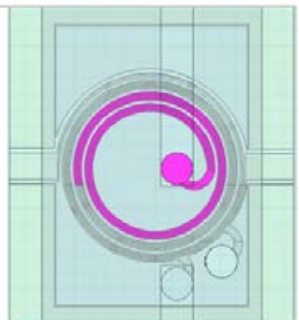

liquid position 3

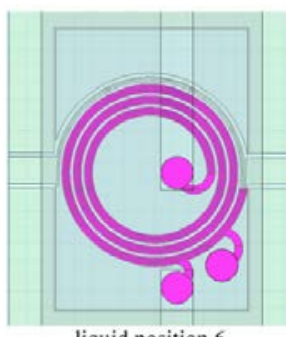

liquid position 6

Fig. 5 Liquid position for the different characterized states 
(a)

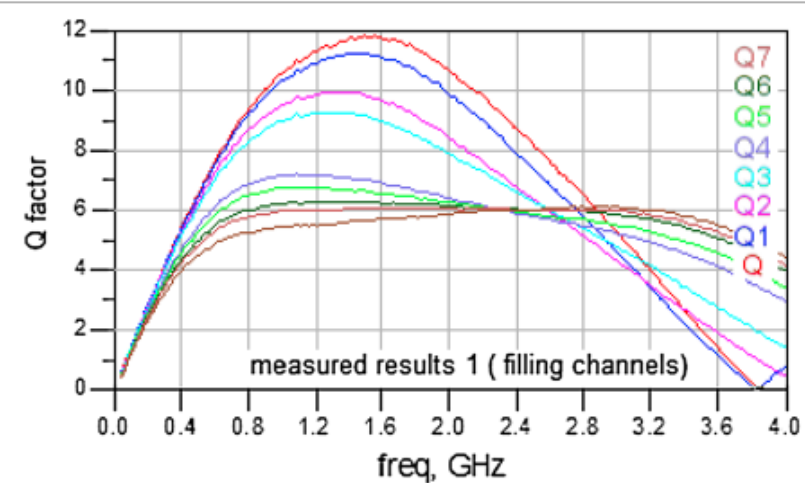

(b) $5.800 \mathrm{E}-9$

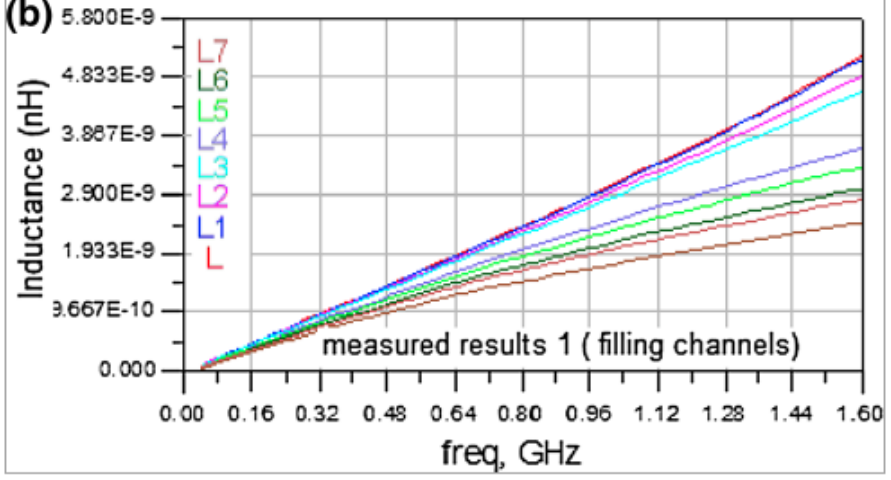

Fig. 6 Measured results 1 (filling channels) a quality factors and $b$ inductor for different salt water position

(a)

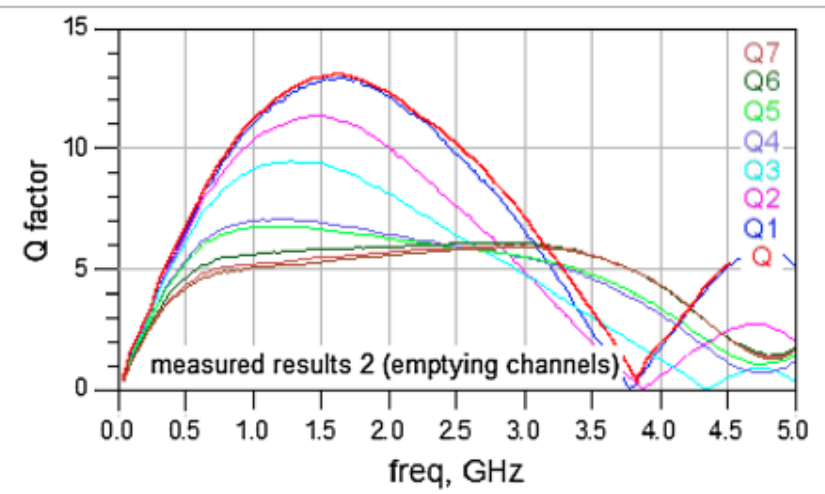

(b) $5.40 \mathrm{E}-9$

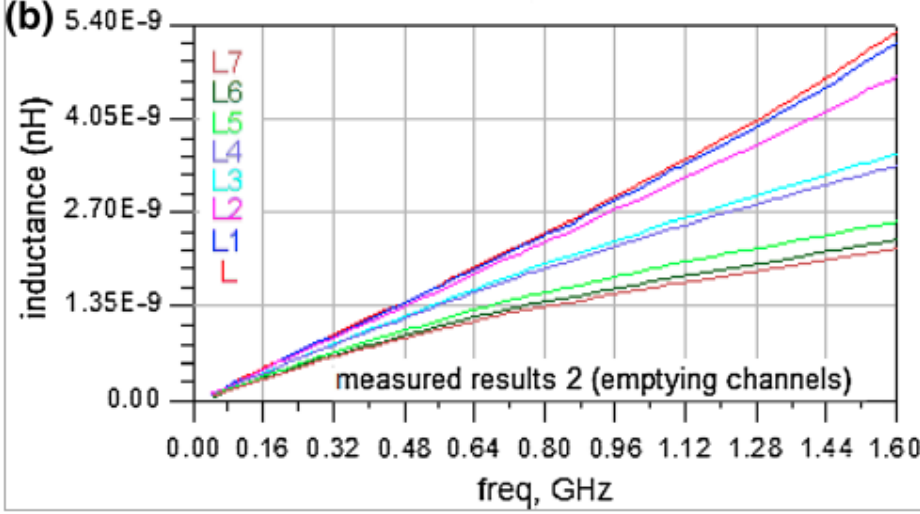

Fig. 7 Measured results 2 (emptying channels) a quality factors and $b$ inductor for different salt water position 

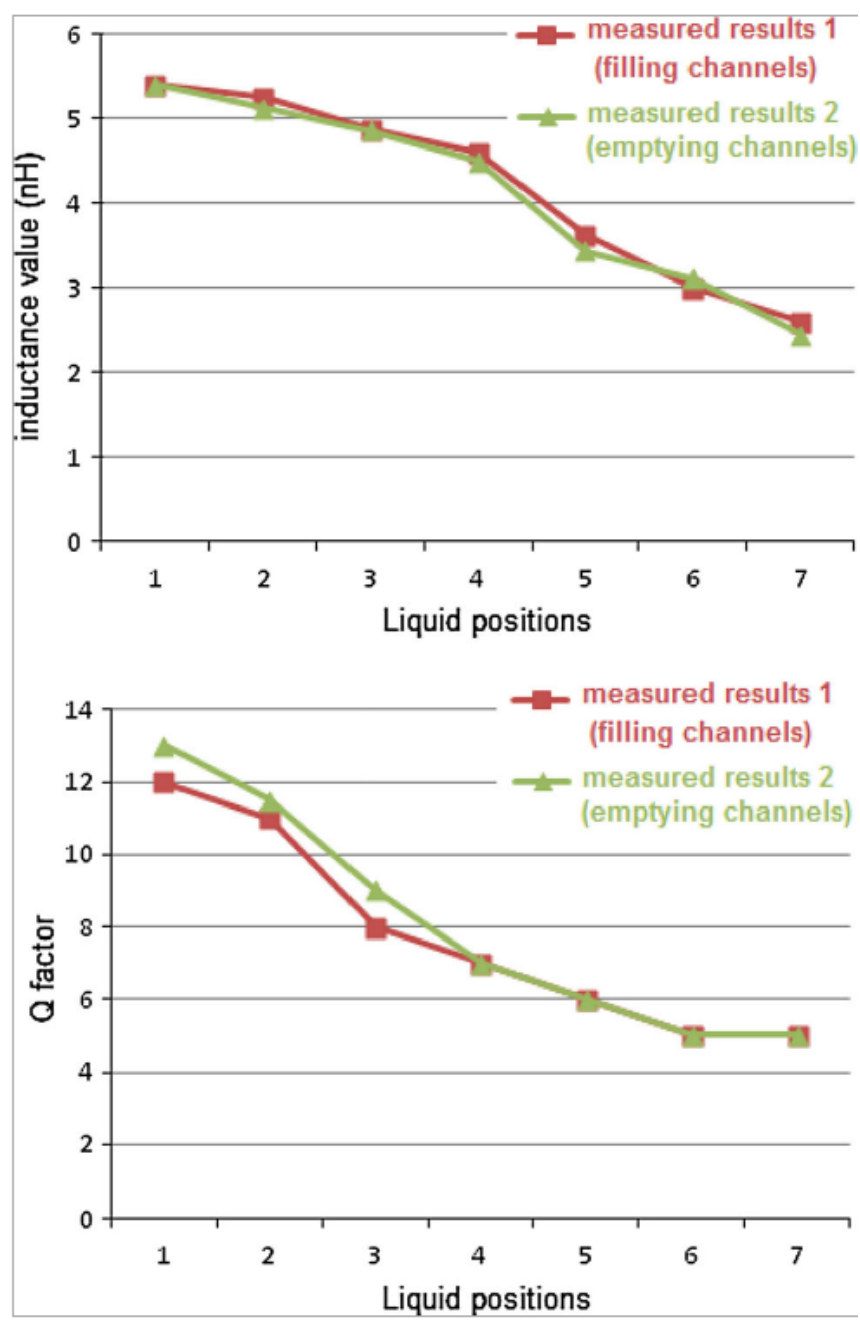

Fig. 8 Comparison between measured results 1 (filling channels) and measured results 2 (emptying channels) characteristics of the variable inductance at $1.6 \mathrm{GHz}$ for different salt water positions

\begin{tabular}{llllll}
\hline $\begin{array}{l}\text { Liquid } \\
\text { position }\end{array}$ & $\begin{array}{l}\text { Measured results } 1 \\
\text { (filling channels) }\end{array}$ & & & $\begin{array}{l}\text { Measured results } 2 \\
\text { (emptying channels) }\end{array}$ \\
\cline { 2 - 3 } \cline { 5 - 6 } & $\begin{array}{l}\text { Inductance } \\
\text { value }(\mathrm{nH})\end{array}$ & $Q$ factor & & $\begin{array}{l}\text { Inductance } \\
\text { value }(\mathrm{nH})\end{array}$ & $Q$ factor \\
\hline 1 & 5.4 & 12 & & 5.4 & 13 \\
2 & 5.25 & 11 & & 5.13 & 11.5 \\
3 & 4.87 & 8 & & 4.86 & 9 \\
4 & 4.6 & 7 & 4.5 & 7 \\
5 & 3.62 & 6 & 3.44 & 6 \\
6 & 3 & 5 & 3.11 & 5 \\
7 & 2.6 & 5 & 2.45 & 5 \\
\hline
\end{tabular}

Table 1 Comparative measured results 


\begin{tabular}{|c|c|c|c|c|c|c|}
\hline References & Inductance value $(\mathrm{nH})$ & $\begin{array}{l}\text { Tuning } \\
\text { range }\end{array}$ & $\begin{array}{l}\text { Quality } \\
\text { factor }\end{array}$ & Frequency & $\begin{array}{l}\text { Mechanical } \\
\text { actuation }\end{array}$ & $\begin{array}{l}\text { Year of } \\
\text { publication }\end{array}$ \\
\hline Zhou, Sun and Carr (1999) & 100 down to $2 \mathrm{nH}$ & 3.3 & $>100$ discontinuous & $\mathrm{GHz}$ & Yes & 1999 \\
\hline Gel et al. (2002) & 7.2 down to $0.25 \mu \mathrm{H}$ & $>28$ & n.c & $\mathrm{KHz}$ & Yes & 1999 \\
\hline Lubecke et al. (2001) & Few nH & $30 \%$ & 5 & $\mathrm{GHz}$ & Yes & 2001 \\
\hline Okada et al. (2006) & Few $n \mathrm{H}$ at few $\mu \mathrm{H}$ & 3 & 4 & $\mathrm{GHz}$ & Yes & 2002 \\
\hline Zine-El-Abidine et al. (2003) & Few nH & $13 \%$ & $<1$ & $\mathrm{GHz}$ & Yes & 2003 \\
\hline Sugawara et al. (2004) & 5.8 down $3.8 \mathrm{nH}$ & $30 \%$ & 4 & $\mathrm{GHz}$ & Yes & 2004 \\
\hline Tassetti et al. (2004) & Few nH & $50 \%$ & 7 & $\mathrm{GHz}$ & $\begin{array}{l}\text { Yes electrostatic } \\
\text { actuation }\end{array}$ & 2005 \\
\hline Okada et al. (2006) & Few nH & $>50 \%$ & 50 & $\mathrm{GHz}$ & Yes & 2006 \\
\hline Chang and Sivoththaman (2006) & $5.6-8.2 \mathrm{nH}$ & $32 \%$ & 15 & $\mathrm{GHz}$ & Thermal actuation & 2006 \\
\hline Velden et al. (1999) & Few $n \mathrm{H}$ & $>80 \%$ & 26 & $\mathrm{GHz}$ & Electro-thermal & 2009 \\
\hline Our work & 2.6-5.4 reversible 5.4-2.6 & $>107 \%$ & 12 & $\mathrm{GHz}$ & Fluidic & 2013 \\
\hline
\end{tabular}

Table 2 Comparative result of various works presented in literature

\section{Conclusion}

We have fabricated and evaluated RF MEMS continuous reversible variable inductor using photosensitive lamination process and MEMS technology. Experiments give very interesting results compared to those obtained by the different approaches experienced up to now. The tuning range of the inductance is approximately $107 \%$ and Q-factor is approximately 12 . To prove the reversibility of the inductor, two cases were studied: filling and emptying of channels. Variable inductor can be exploited in the design of components, subsystems and/or systems in mobile communication systems to achieve new compatibility and improved electrical performance over a wide range and frequency, smaller size, lower power consumption and less weight.

\section{References}

Abgrall P, Lattes C, Cone'de'ra V, Dollat X, Collin S, Gue' AM (2006), A novel fabrication method of flexible and monolithic 3D microfluidic structures using lamination of SU-8 films. J Micromech

Microeng 16:113-121

Chang S, Sivoththaman S (2006), A tunable RF MEMS inductor on silicon incorporating an amorphous silicon bimorph in a lowtemperature process IEEE Electron Device Lett 27:905-908

Fulcrand R, Jugieu D, Escriba C, Bancaud A, Bourrier D, Boukabache, A, Gue' AM (2009) Development of a flexible microfluidic system integrating magnetic micro-actuators for trapping biological species. J Micromech Microeng 19:105019

Gel M, Takeuchi S, Shimoyama I (2002) Fabrication method for out of-plane, micro-coil by surface micromachining. Sensors Actuators A 97(98):702-708

Ito $\mathrm{Y}$, Yoshihar Y, Sugawara H, Okada K, Masu KA (2005), 1.3-2.8 GHz wide range CMOS LC-VCO using variable inductor. In: Proceedings of the IEEE asian solid-state circuits conference, pp 265-268 Kim J-I, Peroulis D (2009) Tunable MEMS spiral inductors with optimized RF performance and integrated large-displacement electrothermal actuators. IEEE Trans Microw Theory Tech 57:22762283

Lubecke VM, Barber B, Chan E, Lopez D, Gross ME, Gammel P (2001) Self-assembling MEMS variable and fixed RF inductors. IEEE Trans Microw Theory Tech 49(11): 2093-2098

Lucyszun S, Robertson ID (1994) High performance MMIC Narrow band filter using tunable active inductors IEEE Microwave and Millimeter-wave monolithic circuits Symposium

Okada K, Sugawara H, Ito H, Itoi K, Sata M, Abe H, Ito T, Masu K (2006) On-chip high-Q variable inductor using wafer-level chipscale package technology IEEE Trans Electron Devices 53: 2401-2406

Sarkar N, Yan D, Ellis M, Horne E, Lee J B, Lu H, Mansour R, Nallani A and Skidmore G 2005 Microassembled tunable MEMS inductor Int Conf Micro Electro Mech Sys 183-6 Sugawara H, Yoshihara Y, Ito H, Okada K, Masu K (2004) Widerange RF variable inductor on Si CMOS chip with MEMS actuator. In: Proceedings of the 34th European Microwave Conf, pp 701-4 
Tassetti CM, Lissorgues G, Gilles JP (2004) New tunable RF MEMS microinductors design. J

Micromech Microeng 14:S17-S22

Velden T, Stefan D, Obermeir E (1999) Micro-coil with movable core for application in an inductive displacement sensor. J Micromech Microeng 9:119-122

Yokoyama Y, Fukushige T, Hata S, Masu K, Shimokohbe A (2003) On-chip variable inductor using microelectromechanical systems technology Japan. J Appl Phys 42:2190-2192

Yoshihara Y, Sugawara H, Ito H, Okada K, Masu K (2005) Wide tuning range LC-VCO using variable inductor for reconfigurable RF circuit. IEICE Trans Fundam Electron Commun Comput Sci E88-

$A(2): 507-512$

Zhou S, Sun X-Q, Carr WN (1999) A monolithic variable inductor network using microrelays with combined thermal and electrostatic actuation. J Micromech Microeng 9:45-50

Zine-El-Abidine I, Okoniewski M, McRory JG (2003) A new class of tunable RF MEMS inductors. In: Proceedings of the international conference MEMS, nano, and smart systems, pp 114-115

Zine-El-Abidine I, Okoniewski M, McRory JG (2005) Tunable radio frequency MEMS inductors with thermal bimorph actuators. J Micromech Microeng 15:2063-2068 